\title{
A novel anti-p21Ras scFv antibody reacting specifically with human tumour cell lines and primary tumour tissues
}

\author{
Ju-Lun Yang ${ }^{1 *}$, Du-Xian Liu², Shi-Jian Zhen², Yun-Gang Zhou², Dai-Jun Zhang ${ }^{1}$, Li-Ying Yang ${ }^{1}$, Hao-Bing Chen ${ }^{1}$ \\ and Qiang Feng ${ }^{1}$
}

\begin{abstract}
Background: The ras genes play an important role in the development and progression of human tumours. Neutralizing Ras proteins in the cytoplasm could be an effective approach to blocking ras signalling. In this study, we prepared anti-p21Ras single chain fragment variable antibody (scFv) and investigated its immunoreactivity with human tumours.

Methods: The coding sequences of $\mathrm{H}$-ras, $\mathrm{K}$-ras, and $\mathrm{N}$-ras were separately ligated into the vector pET-28a(+). Then, recombinant expressing plasmids were induced by IPTG for p21Ras expression in E. coli. Hybridoma cell lines producing anti-p21Ras monoclonal antibodies were isolated using wildtype p21Ras proteins as immunogens. Antip21Ras scFv antibody was prepared from the hybridoma by the phage scFv display method. The immunoreactivity of the anti-p21Ras monoclonal antibody and the scFv antibody was identified by ELISA and immunocytochemistry.

Results: We prokaryotically expressed wildtype H-p21Ras, K-p21Ras and N-p21Ras and generated the hybridoma cell line KGH-R1, producing anti-p21Ras monoclonal antibodies. It was demonstrated that KGH-R1 monoclonal antibody could recognize wildtype and mutated H-p21Ras, K-p21Ras and N-p21Ras in human tumour cell lines. In all 14 types of primary human cancer tissues tested, the monoclonal antibody presented strong immunoreactivity but showed weak or negative immunoreactivity in the corresponding normal tissues. Subsequently, we prepared anti-p21Ras scFv from hybridoma KGH-R1, which showed the same immunoreactivity as the original monoclonal antibody. Sequence analysis demonstrated that the nucleotides and amino acids of the scFv exhibited an approximately $50 \%$ difference from the anti-p21Ras scFv reported previously.
\end{abstract}

Conclusions: This study presents a novel anti-p21Ras scFv antibody. Our data suggest that the scFv may be useful for ras signalling blockage and may be a potential therapeutic antibody for ras-derived tumours.

Keywords: p21Ras, scFv, Tumour, Immunoreactivity, Monoclonal antibody

\section{Background}

Because of the important role of ras in carcinogenesis and progression, the ras signalling pathway has attracted considerable attention as a target for anticancer therapy. The ras gene product, p21Ras, is a monomeric membranelocalized G protein of $21 \mathrm{kD}$, which functions as a molecular switch converting signals from the cell membrane to the nucleus and linking receptor and nonreceptor tyrosine

\footnotetext{
*Correspondence: yangjulun@sina.com

${ }^{1}$ Department of Pathology, Kunming General Hospital/Kunming Medical

University, Kunming 650032, Yunnan Province, China

Full list of author information is available at the end of the article
}

kinase activation to downstream cytoplasmic or nuclear events. The biological effects of p21Ras depend on its biochemical properties of being a small GTP-binding protein and on its correct cellular location at the cytoplasmic face of the plasma membrane [1]. Thus, the neutralization of p21Ras proteins in the cytoplasm using specific antibodies may block ras signalling and constitute a promising therapeutic strategy [2].

It is well known that whole antibodies can penetrate cells only with difficulty due to their large molecular size. In recent years, a series of low-molecular-weight antibodies containing antigen-binding domains have been 
explored to develop antibody-based drugs with better tumour penetration, such as antigen-binding fragment [3], single chain fragment variable (scFv) [4], and single-domain antibodies [5]. It has been found that $\mathrm{scFv}$ antibodies penetrate the cell membrane better than whole antibodies $[6,7]$ and result in no immunological rejections due to lacking the Fc fragment $[8,9]$, giving them advantages as intracellular immunization and therapeutic antibodies. Currently, scFv antibodies have been applied in many fields, including anti-viral and cancer therapy [10-12].

Both overexpression and mutation can activate ras genes. The overexpression of p21Ras has been detected in many human tumours [13-17]. The overexpression of ras family members led to the acquired resistance of cancer to cetuximab treatment [18]. It has been found that ras mutations are present in approximately $33 \%$ of all human tumours [19]. K-ras mutations occur frequently in non-small-cell lung, colorectal, and pancreatic carcinomas; $H$-ras mutations are common in bladder, kidney, and thyroid carcinomas; and N-ras mutations are found in melanoma, hepatocellular carcinoma, and haematologic malignancies [20]. However, previously reported anti-p21Ras antibodies were derived from mutated p21Ras antigen [21-23]. In this study, we isolated hybridoma cell lines producing anti-p21Ras monoclonal antibodies, using wildtype p21Ras proteins as immunogens, prepared anti-p21Ras scFv antibodies from the hybridomas, and then investigated their immunoreactivity with human tumour cell lines and primary tumour tissues.

\section{Methods}

\section{Preparation of the wildtype p21Ras proteins}

The coding sequences (CDS) of the $H$-ras, $K$-ras, and $N$ ras genes were chemically synthetized according to their wildtype mRNA sequences published in NCBI GenBank: NM_005343 for H-ras, M54968 for K-ras, and BC005219 for N-ras. The restriction enzyme Bam HI cutting site GGATCC was ligated at the $5^{\prime}$ end of the CDS, and the Hind III cutting site AAGCTT was ligated at the 3 ' end during synthesis. After digestion with Bam $\mathrm{HI}$ and Hind III, the three CDS fragments were ligated separately into the vector $\mathrm{pET}-28 \mathrm{a}(+)$ by T4 ligase. Then, recombinant expressing plasmids were transformed into E. coli BL21(DE3) and screened by kanamycin, induced by IPTG for p21Ras expression [24]. Expressed p21Ras proteins were purified by $\mathrm{Ni}^{2+}$-NTA resin with the mild denaturant urea and then underwent SDS-PAGE analysis, followed by dialysis for renaturation.

\section{Preparation of hybridomas producing broad-spectrum anti-p21 Ras mAb}

Balb/c mice were immunized by injection with wildtype H-p21Ras expressed prokaryotically. The mouse splenic B lymphocytes were fused with myeloma cell lines SP2/
0. After selective culture using HAT selective culture medium, the fused hybridoma cells were screened by an indirect ELISA method with all three wildtype p21Ras proteins and then cloned and subcloned to obtain hybridoma cell lines producing monoclonal antibodies against wildtype H-p21Ras, K-p21Ras and N-p21Ras. All hybridoma cell lines were subcloned twice. Finally, the hybridoma cell lines were injected into the peritoneal cavity of Balb/c mice to produce monoclonal antibodies [21]. A completed ARRIVE guidelines checklist is included in Additional file 1. Human cancer cell lines were used to identify the immunoreactivity of the monoclonal antibodies by Western blot. Primary tumour tissues and their corresponding normal tissues were employed to investigate the tumour reactivities of the monoclonal antibodies by immunohistochemical staining, and the results were described by HSCOREs [25].

\section{Construction of scFv phage display library}

Hybridoma cell line KGH-R1, which produced excellent broad-spectrum anti-p21Ras mAb, was used to construct a phage scFv display library. Total RNA was isolated from KGH-R1 cells using RNAiso plus (MrcGene) and reverse transcribed to cDNA using the RevertAid ${ }^{\mathrm{TM}}$ $\mathrm{H}$ Minus First Strand cDNA Synthesis Kit (Fermentas). The heavy chain variable region $\left(\mathrm{V}_{\mathrm{H}}\right)$ and light chain variable region $\left(\mathrm{V}_{\mathrm{L}}\right)$ were amplified using primers provided by the Recombinant Phage Antibody System (GE Healthcare, RPAS). A DNA linker complementary to the $3^{\prime}$ end of $\mathrm{V}_{\mathrm{H}}$ and $5^{\prime}$ end of $\mathrm{V}_{\mathrm{L}}$ was ligated between the $\mathrm{V}_{\mathrm{H}}$ and $\mathrm{V}_{\mathrm{L}}$ fragments by overlapping extended PCR amplification to construct the $\mathrm{scFv}$ gene.

The phage scFv display library was constructed according to the RPAS system manual (GE Healthcare). Briefly, the scFv fragment genes and the phagemid pCANTAB-5E were sequentially digested with the $S f i$ I and Not I restriction enzymes. After purification by agarose gel extraction, both the scFvs fragments and the pCANTAB-5E vector with Sfi I and Not were ligated using T4 DNA ligase, transformed into competent E. coli TG1 cells, and cultured on SOBAG plates (SOB-AG, containing $100 \mu \mathrm{g} / \mathrm{ml}$ ampicillin and $2 \%$ glucose) at $37{ }^{\circ} \mathrm{C}$. All of the bacterial single colonies that grew on the SOBAG plate were collected, mixed and cultured in $2 \times$ YTAG medium. The helper phage M13K07 at $10^{11} \mathrm{pfu}$ was added to the collections and co-cultured at $30{ }^{\circ} \mathrm{C}$ for $1 \mathrm{~h}$ to obtain recombinant phages expressing the $\mathrm{scFv}$ antibodies and g3p fusion proteins on the surface. The $\mathrm{scFv}$ phages were purified and concentrated by polyethylene glycol (20\% PEG8000, $2.5 \mathrm{~mol} / \mathrm{L} \mathrm{NaCl}$ ). The pellet was resuspended in PBS to obtain the phage scFv display library.

\section{Enrichment of scFv phage}

The phage scFv display library underwent three rounds of panning using H-p21Ras, K-p21Ras and N-p21Ras 
protein antigens, respectively. Briefly, the flask was coated with p21Ras protein dissolved in $0.1 \mathrm{mM} \mathrm{NaHCO}$. After blocking with BSA, the library was added to the flask and incubated at $37{ }^{\circ} \mathrm{C}$ for $2 \mathrm{~h}$, followed by washing with PBST (containing $0.05 \%$ tween-20, pH 7.4) 10 times, followed by washing PBS (without Tween-20) an additional 10 times to remove unbound phage particles. Specifically bound phages were eluted with $0.1 \mathrm{M} \mathrm{HCL/glycine}$ (containing $0.1 \% \mathrm{BSA}, \mathrm{pH} 2.2$ ). The eluent was neutralized with $\mathrm{pH} 9.0$ Tris $/ \mathrm{HCl}$, was used to infect TG1 cells and was then rescued with helper phage M13K07. These enriched $\mathrm{scFv}$ phages were used in the next round of panning [26, 27]. In each panning round, the numbers of input and output phages were counted using the double agar layer method.

\section{Identification of scFv-phages}

E. coli TG1 cells were infected by the final enriched phage pools and cultured on an SOB-AG plate. Single colonies were picked and rescued individually with M13K07 in 96well plates. The phages from individual wells were assayed by ELISA to detect their specific antigen binding activities, utilizing p21Ras proteins as antigens, scFv-phage as primary antibody, and HRP-conjugated mouse anti-M13 $\mathrm{mAb}$ as second antibody. The positive phages were further identified by Sfi I and Not I enzyme digestion and PCR amplification with pCANTAB-5E primers (forward, S1: 5-CAACGTGAAAAAATTATTATTCGC-3; reverse, S6: 5-GTAAATGAATTTTC TGTATGAGG-3). The amplified products were ligated into a pMD18-T vector for sequence analysis.

\section{Bioinformatics analysis of scFv gene and 3D modelling}

The sequence of the $\mathrm{scFv}$ gene was blasted with known murine genes for homology analysis in the GenBank database, as described previously [28]. The amino acid residues, CDRs and FRs were determined according to the IMGT numbering system and Kabat by IgBLAST [28]. The 3D structure of $\mathrm{scFv}$ antibody was generated by SWISS-MODEL [29, 30].

\section{Expression of soluble scFv antibodies}

The expression of soluble scFv antibodies was performed according to the manual and reference [31]. Briefly, the p21Ras-positve phages were used to infect HB2151 cells and cultured in plates. A single colony was picked and grown overnight to express soluble anti-p21Ras scFv antibodies with E-tag peptide at the end through the induction of IPTG. The soluble scFv antibodies were extracted from the HB2151 culture and concentrated by PEG8000/NaCl.

\section{Immunocytochemistry/immunohistochemistry and Western blot}

Human tumour cell lines harbouring wildtype or mutated Ras [32, 33], primary tumour tissues and the corresponding normal tissues were employed to detect the immunoreactivities of the scFv antibodies by immunohistochemical staining. The soluble scFv antibodies were used as the primary antibody, whereas Anti-E-tag monoclonal antibody conjugated with HRP served as the second antibody to bind E-tag protein ligated to the end of the scFv antibody. The scFv immunoreactivity with p21Ras was further detected by Western blot in the tumour cell lines MDA-MB-435, MDA-MB-231 and SKOV3 (ATCC USA) and the normal cell line KMB17 (normal human embryonic diploid lung fibroblast cell, constructed by the Institute of Medical Biology, Chinese Academy of Medical Sciences). $\beta$-actin was used as a control, with anti- $\beta$-actin monoclonal antibody conjugated with HRP.

\section{Ethics statement}

This study including animal work has the approval of the Ethics Board of Kunming General Hospital and is also in accordance with the Helsinki Declaration of 1975. Written informed consent was obtained from every patient. All human tissues were processed anonymously.

\section{Results}

Preparation of hybridomas and anti-p21Ras monoclonal antibodies

By cloning the CDS of the H-ras, K-ras, $N$-ras genes into pET-28(+) vectors, we constructed a prokaryotically expressive vector (Fig. 1a, b) that effectively expressed $\mathrm{H}$ p21Ras, K-p21Ras and N-p21Ras protein in E. coli BL21. SDS-PAGE analysis showed that the apparent molecular weight of the three p21Ras proteins was $25 \mathrm{KD}$ (Fig. 1c). The purity of p21Ras protein was more than $95 \%$.

H-p21Ras was used as an immunogen to immunize $\mathrm{BALB} / \mathrm{c}$ mice to isolate hybridomas. To achieve monoclonal antibodies that simultaneously recognized $\mathrm{H}$ p21Ras, K-p21Ras and N-p21Ras, the three p21Ras were used as antigens to screen the hybridomas in an ELISA assay. In total, we obtained 13 hybridomas that produced monoclonal antibodies against the three different p21Ras proteins. Karyotype analysis showed that the median chromosome numbers of the 13 hybridomas were 97-100. Immunochromatography indicated that the monoclonal antibodies produced by all 13 hybridomas were of the $\operatorname{IgG} 2 \mathrm{~b} / \mathrm{k}$ subtype. Monoclonal antibodies in ascites reached a high titre of 1:128000. The immunoreactivities of the monoclonal antibody KGH-R1 were determined by Western blot and immunohistochemistry. The KGH-R1 monoclonal antibody demonstrated positive immunoreactivities in all 13 human solid tumour cell lines and 2/6 leukaemia cell lines (Table 1 ). In all 14 types of 


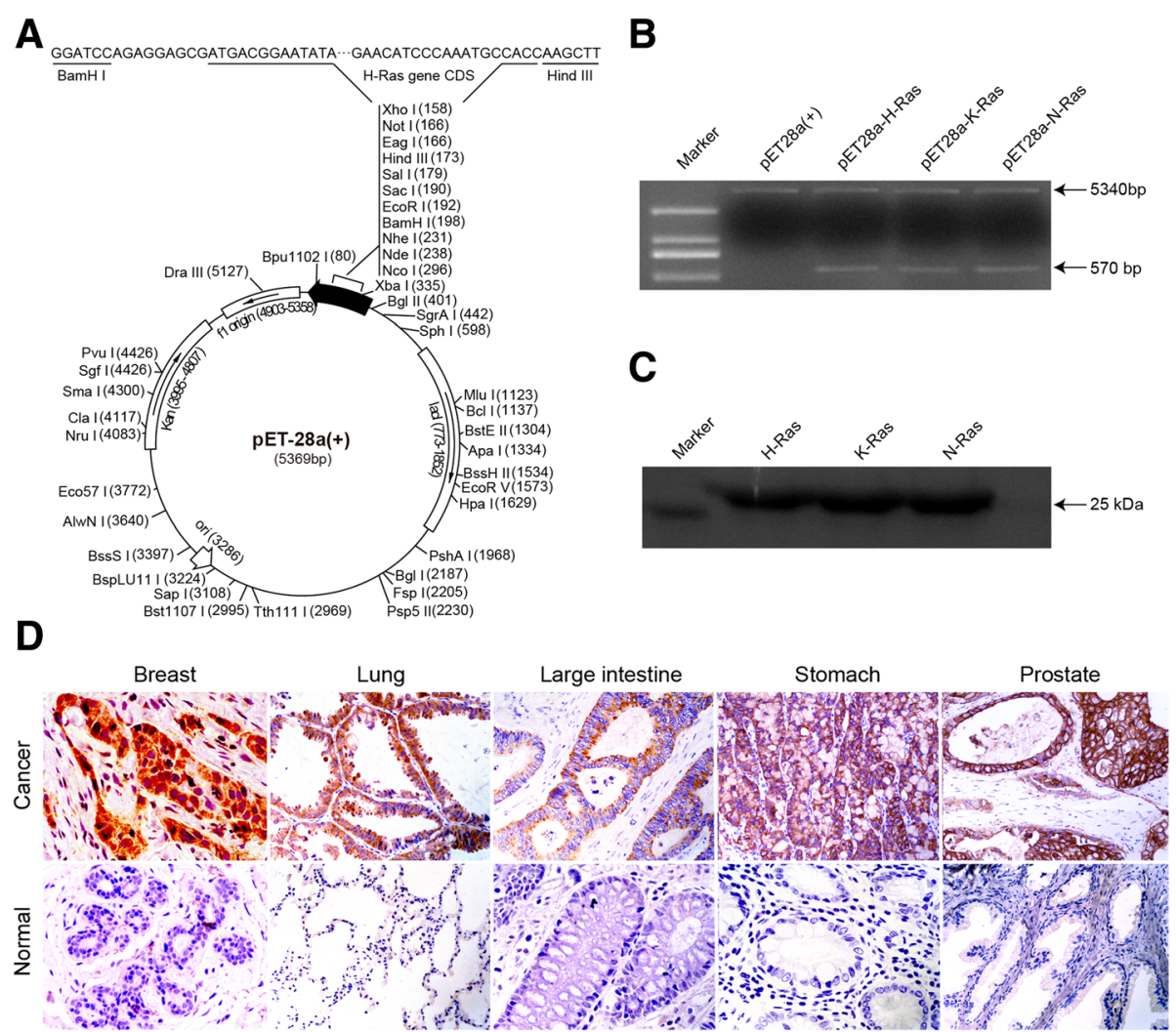

Fig. 1 Wildtype p21Ras proteins and anti-p21Ras monoclonal antibodies. a The plasmid map of recombinant pET-28a(+) vector expressing H-ras, in which H-ras gene CDS with Bam HI and Hind III restriction enzyme sites was cloned into a pET-28a(+) vector with a histidine tag-compatible end. $\mathbf{b}$ The three recombinant pET28a(+) plasmids were digested into two fragments by Bam HI and Hind III, the 570 bp of the ras gene CDS and $5340 \mathrm{bp}$ of the pET-28a(+) vector. c SDS-PAGE analysis showed that the molecular weight of the three p21Ras proteins with His tag was $25 \mathrm{kDa}$. d KGH-R1 monoclonal antibody against three p21Ras proteins demonstrated strong immunoreactivity to cancer tissues but negative immunoreactivity to corresponding normal tissues

primary human cancer tissues tested here, the monoclonal antibody presented strong immunoreactivity but showed weak or negative immunoreactivity in the corresponding normal tissues (Table 2, Fig. 1d).

\section{Construction and panning of scFv phage display library}

The scFv gene consists of a heavy chain variable region $\left(V_{H}\right)$ and a light chain variable region $\left(V_{L}\right)$, joined by a neutral linker (Fig. 2a). We amplified $\mathrm{V}_{\mathrm{H}}(340 \mathrm{bp})$ and $\mathrm{V}_{\mathrm{L}}(320 \mathrm{bp}$ ) from the cDNA of the KGH-R1 hybridoma. Then, we connected both to DNA linker by overlapping extended PCR to construct a $750 \mathrm{bp} \mathrm{scFv}$ gene (Fig. 2b). The $\mathrm{scFv}$ gene repertoire was ligated to the phagemid pCANTAB $5 \mathrm{E}$ and then transformed into competent TG1 cells and grown in SOBAG plates, obtaining $1 \times 10^{7}$ TG1 colonies transformed by the recombinant phage plasmids (Fig. 2c). We collected all of the TG1 colonies, co-cultured them with $\mathrm{M} 13 \mathrm{KO} 7$ helper phages, and established the scFv phage display library, in which scFvg3p fusion proteins were expressed at the tips of the phages. To obtain phages expressing anti-p21Ras scFv antibodies from the library, the library was selected and panned using the H-p21Ras, K-p21Ras, and N-p21Ras proteins, in turn. After three rounds of panning, the eluted phages were maintained at $1 \times 10^{6} \mathrm{pFU} / \mathrm{mL}$, and the number of input phage pools was maintained at $1 \times 10^{9}$ pFU/mL (Fig. 2d).

\section{Characteristics of anti-p21Ras scFv antibodies}

To obtain monoclonal phages expressing anti-p21Ras scFv antibodies, we infected TG1 cells with the enriched scFv phage pool and plated them on SOBAG plates. Then, 40 colonies were rescued by M13K07. Indirect ELISA tests showed that all 40 colonies expressed scFv antibodies that could bind H-p21Ras, K-p21Ras and Np21Ras simultaneously. Recombinant phagemids were isolated from each of the 40 colonies and digested by $S f i$ I and Not I and then ligated with PMD18-T vector for DNA sequencing. Sequence analysis demonstrated that the sequences of the 40 colonies were the same. The number of amino acids and complementary determining regions (CDRs) of the $\mathrm{V}_{\mathrm{H}}$ and $\mathrm{V}_{\mathrm{L}}$ domains were determined using 
Table 1 Immunoreactivity of KGH-R1 mAb in human tumour cell lines

\begin{tabular}{llll}
\hline Tumour cell lines $^{\text {a }}$ & Ras status $^{\text {b }}$ & Western blot & Immunocytochemistry \\
\hline QGY7703 & Unknown & + & + \\
SMMC7721 & Unknown & + & + \\
HepG2 & N, mutant & + & + \\
BGC823 & Unknown & + & + \\
MKN28 & Unknown & + & + \\
HCT116 & K, mutant & + & + \\
T24 & H, mutant & + & + \\
SKOV3 & Unknown & + & + \\
MDA-MB-231 & K, mutant & + & + \\
MDA-MB-435 & Unknown & + & + \\
MCF7 & Unknown & + & + \\
HeLa & Wildtype & + & + \\
Hep2 & Unknown & + & + \\
C8166 & Unknown & + & + \\
K562 & Unknown & + & + \\
Daud I & Unknown & - & - \\
HL60 & N, mutant & - & - \\
MT4 & Unknown & - & - \\
THP1 & N, mutant & - & - \\
\hline
\end{tabular}

${ }^{a}$ QGY7703, SMMC7721, HepG2: hepatocarcinoma; BGC853, MKN28: gastric cancer; HCT116: colorectal cancer; T24: bladder cancer; SKOV3: ovary cancer; MDA-MB-231, MDA-MB-435, MCF7: breast cancer; HeLa: cervical cancer; Hep2: laryngocarcinoma; C8166, K562, Daud I, HL60, MT4, THP1: leukaemia. bublished data

Table 2 Immunoreactivity of $\mathrm{KGH}-\mathrm{R} 1 \mathrm{mAb}$ in human tumours and corresponding normal tissues

\begin{tabular}{|c|c|c|c|}
\hline \multirow[t]{2}{*}{ Tumour } & \multirow[t]{2}{*}{ Cases } & \multicolumn{2}{|c|}{ Immunoreactivity (HSCOREs ${ }^{\mathrm{a}}$ ) } \\
\hline & & $\begin{array}{l}\text { Primary tumour } \\
\text { tissues }\end{array}$ & Normal tissues \\
\hline Colorectal cancer & 30 & $208.69 \pm 84.40$ & $6.88 \pm 1.53$ \\
\hline Gastric cancer & 30 & $155.29 \pm 87.50$ & $7.86 \pm 2.79$ \\
\hline Oesophageal cancer & 30 & $163.73 \pm 66.00$ & $8.50 \pm 3.28$ \\
\hline Bladder cancer & 30 & $146.76 \pm 95.36$ & $8.10 \pm 2.43$ \\
\hline Lung adenocarcinoma & 30 & $238.63 \pm 72.00$ & $7.00 \pm 1.77$ \\
\hline Lung squamous cell carcinoma & 30 & $178.26 \pm 83.99$ & $7.00 \pm 1.77$ \\
\hline Lung small cell carcinoma & 30 & $134.38 \pm 91.58$ & $7.00 \pm 1.77$ \\
\hline Papillary thyroid carcinoma & 30 & $239.33 \pm 75.51$ & $8.43 \pm 2.32$ \\
\hline Hepatocarcinoma & 30 & $184.38 \pm 96.75$ & $11.29 \pm 5.51$ \\
\hline Prostate carcinoma & 30 & $114.77 \pm 70.59$ & $13.00 \pm 4.24$ \\
\hline Breast cancer & 30 & $197.46 \pm 56.33$ & $9.23 \pm 3.19$ \\
\hline Endometrial cancer & 30 & $139.29 \pm 86.00$ & $15.75 \pm 5.72$ \\
\hline Glioma & 30 & $97.60 \pm 8.85$ & $17.30 \pm 8.32$ \\
\hline Renal cell carcinoma & 30 & $117.50 \pm 73.86$ & $16.00 \pm 5.85$ \\
\hline
\end{tabular}

${ }^{\mathrm{a} M e a n} \pm \mathrm{SD}$
IgBLAST. KGHR1-scFv had 738 nucleotides encoding 246 amino acids, of which $\mathrm{V}_{\mathrm{H}}$ consisted of 117 amino acids, $\mathrm{V}_{\mathrm{L}}$ consisted of 114 amino acids, and the flexible amino acid linker consisted of 15 amino acids. Both the $\mathrm{V}_{\mathrm{H}}$ and $\mathrm{V}_{\mathrm{L}}$ fragments had 3 CDR regions and $4 \mathrm{FR}$ regions (Fig 3a). Homology analysis revealed that $\mathrm{V}_{\mathrm{H}}$ belongs to murine subfamily III and that $\mathrm{V}_{\mathrm{L}}$ belongs to the subfamily VII $\mathrm{K}$ chains. We constructed a three-dimensional model of the scFv antibody by the SWISS MODEL method. In the 3D model, scFv consists of the $\mathrm{V}_{\mathrm{H}}$ chain and the $\mathrm{V}_{\mathrm{L}}$ chain connected by a polypeptide linker chain (Fig. $3 b$ ).

Immunoreactivity of soluble anti-p21Ras scFv antibodies Soluble anti-p21Ras scFv antibodies were prepared by infecting the non-amber suppressor $E$. coli strain HB2151 with the recombinant phages. The Western blot assay showed that anti-p21Ras scFv antibody could specifically bind the p21Ras protein in the tested cells (Fig. 3c). We further evaluated the immunoreactivities of $\mathrm{scFv}$ in human tumour cell lines, primary solid tumour tissues and normal tissues by immunohistochemical staining. The results demonstrated that the soluble scFv displayed strong immunostaining in all the human tumour cell lines and all types of primary human cancer tissues tested here. However, all of the corresponding normal tissues showed negative immunostaining. The granular positive signal was mainly located in the cytoplasm and membrane (Table 3, Fig. 3d). The results indicated that the obtained scFv could recognize the p21Ras antigen epitope in tumour cells.

\section{Discussion}

Antibody-based drugs are promising agents for cancer therapy. In recent years, certain antibody drugs have been clinically approved and used frequently in cancer treatment. Trastuzumab, a chimeric monoclonal antibody against Her2 protein, is the most impressive target drug for breast cancer therapy [34, 35]. Rituximab, an anti-CD20 monoclonal antibody, is another of the most effective drugs in B cell malignant lymphoma treatment [36]. The gene ras is a well-known and important oncogene involved in the development and progression of many human tumours, but no antibody drugs targeting the ras gene have been applied clinically. The main reason is that the intracellular location of p21Ras has limited the effects of antibodies because intact antibodies can not penetrate the cell membrane. Thus, small molecular antibodies, such as $\mathrm{scFv}$, are proposed to treat ras-derived tumours.

Because hybridoma cell lines are the most important resources for $\mathrm{scFv}$ [37-39], we established anti-p21Ras hybridomas using prokaryotically expressed wildtype $\mathrm{H}$ p21Ras protein as an immunogen. H-p21Ras, K-p21Ras and N-p21Ras were used to screen the hybridoma clones. 

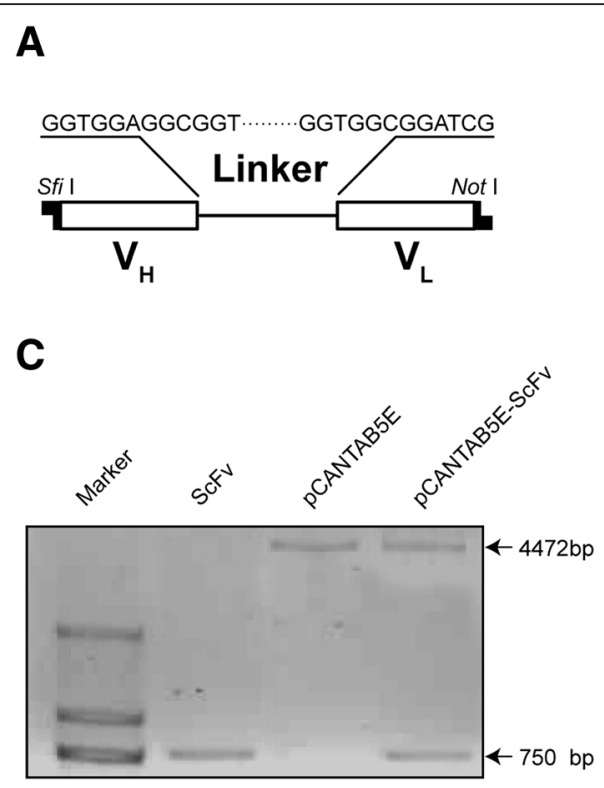

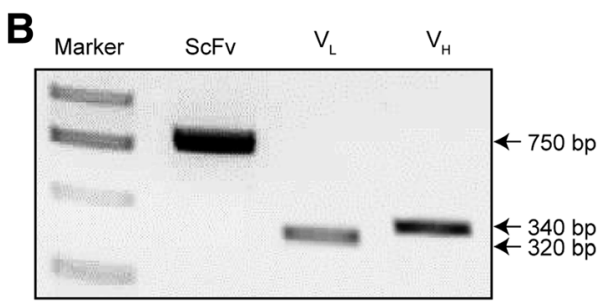

D

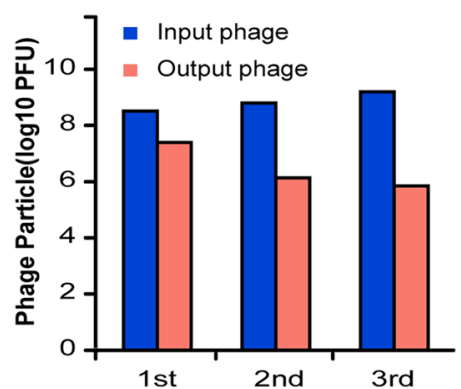

Fig. 2 Preparation of anti p21Ras scFv. a Schematic diagram of scFv. The variable region of the heavy chain $\left(V_{H}\right)$ and the variable region of the light chain $\left(V_{L}\right)$ were combined with a polypeptide linker. b Construction of scFv gene. The 340 bp $V_{H}$ fragment and 325 bp $V_{L}$ fragment were amplified from the cDNA of the KGH-R1 hybridoma. This assembly reaction ultimately produces 750 bp of scFv. c The recombinant pCANTAB5E-scFv plasmid was digested into two fragments by Sfi I and Not I: 750 bp of scFv and 4472 bp of pCANTAB-5E vector. $\mathbf{d}$ The phage-ELISA showed that after three rounds of panning by H-p21Ras, K-p21Ras and N-p21Ras antigens, in turn, the number of output phages (unbound phages) was constant at $1 \times 10^{6} \mathrm{PFU} / \mathrm{ml}$, whereas the number of input phage was constant at $1 \times 10^{9} \mathrm{PFU} / \mathrm{ml}$

Finally, the hybridoma KGH-R1, producing a broadspectrum monoclonal antibody against the three p21Ras proteins, was isolated. Interestingly, the monoclonal antibodies reacted with both wildtype and mutated p21Ras in human tumour cell lines and presented excellent immunoreactivities with the majority of human tumour cell lines and primary tumour tissues but negative immunostaining in the corresponding normal tissues. The characteristics mentioned above give these antibodies important value as therapeutic prodrugs. To our knowledge, this study is the first to use wildtype p21 Ras as an immunogen to prepare monoclonal antibodies. The anti-p21Ras monoclonal antibodies reported previously were derived from mutated p21Ras, of which Y13259 and Y13-238 were generated using p21 protein encoded by the $v$-ras gene of the Harvey murine sarcoma virus as an immunogen [22]. RAP-1 $\sim 5$ were generated utilizing a synthetic H-p21Ras peptide reflecting amino acid positions $10-17$ with a mutation at codon 12 as the immunogen [23]. RASK1 16 were generated using mutated K-p21Ras from Kirsten murine sarcoma virus as the immunogen [21].

Antibody genes can be fused into phage genes, and then the antibodies can be expressed and displayed on the surface of the phages as fusion proteins [40]. The phage display library has thus become the most popular technique for constructing and selecting scFv antibodies from hybridomas or B lymphocytes due to its benefits, such as the high diversity of the antigenic repertoire and the ability to rapidly select specific antibodies [41]. In this study, we employed the phage display library method to isolate scFv antibodies against human p21Ras proteins. Fortunately, we obtained $\mathrm{scFv}$ antibodies that maintained all of the immunoreactivities of the original monoclonal KGH-R1 antibodies, including the recognition of wildtype and mutated p21Ras proteins, reaction with H-p21Ras, K-p21Ras and N-p21Ras, and strong immunostaining in tumour cell lines and primary tumours. These results showed that $\mathrm{scFv}$ is useful for ras signalling blockage and may be a therapeutic antibody for rasderived tumours.

The $\mathrm{scFv}$ antibodies presented here were dramatically different from previous anti-p21Ras scFv in both their nucleotide sequences and their amino acid sequences $[42,43]$. There was a $49.8 \%$ difference from Y13-259 scFv and a $53.73 \%$ difference from Y13-238 scFv, mostly located in the CDRs (Fig. 3a). Our data indicated that KGH-R1 scFv recognizes different antigen epitopes, based on a comparison of Y13-259 scFv and Y13-238 scFv, and it is a novel anti-p21Ras scFv antibody.

\section{Conclusions}

In conclusion, this study presents a novel anti-p21Ras scFv antibody, KGH-R1 scFv, produced by hybridoma and phage $\mathrm{scFv}$ display library methods. Sequence analysis showed that $\mathrm{KGH}-\mathrm{R} 1 \mathrm{scFv}$ antibody has an approximately 


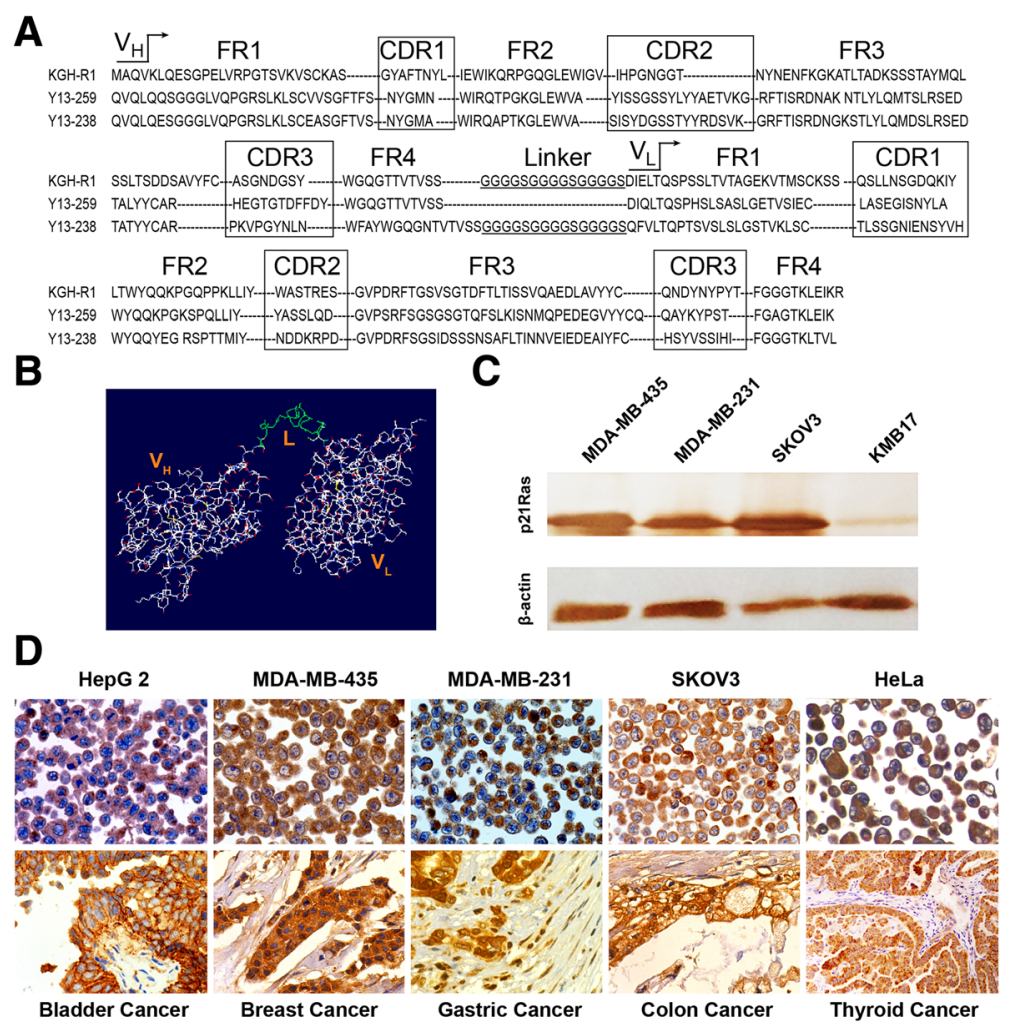

Fig. 3 Bioinformatics and immunoreactivity of the anti-p21Ras scFv. a Amino acid sequence of anti-p21Ras scFv with appropriate regions for framework and CDR residues, differing from the previously reported Y13-159 scFv and Y13-238 scFv. b 3D model of anti-p21Ras scFv generated by bioinformatics. Variable heavy chain $\left(V_{H}\right)$ and light chain $\left(V_{L}\right)$ regions of the antibody were connected by a single 15-amino acid linker ( $L$, green). c Western blot detected anti-p21Ras scFv antibody-specific binding with p21Ras protein in the cells, where strong immunoreactivity was found in p21Ras-overexpressing tumour cell lines; however, weak immunoreactivity was observed in the normal cell line KMB17 with low p21Ras expression. d Immunohistochemistry revealed that anti-p21Ras scFv antibody exhibited strongly positive staining in human tumour cell lines and primary solid tumour tissues

Table 3 Immunoreactivity of KGHR1-scFv antibody in human tumour tissues and cell lines

\begin{tabular}{|c|c|c|c|c|c|}
\hline \multicolumn{4}{|l|}{ Immunoreactivity (HSCOREs ${ }^{\mathrm{a}}$ ) } & \multicolumn{2}{|c|}{ Immunocytochemistry } \\
\hline Tumour tissues & Cases & Primary tumour tissues & Normal tissues & Tumour cell lines & Results \\
\hline Colorectal cancer & 30 & $180.54 \pm 79.21$ & $7.31 \pm 2.13$ & BGC853 & + \\
\hline Gastric cancer & 25 & $150.17 \pm 64.31$ & $7.13 \pm 1.99$ & MKN28 & + \\
\hline Oesophageal cancer & 25 & $151.42 \pm 59.13$ & $8.21 \pm 2.38$ & HCT116 & + \\
\hline Bladder cancer & 25 & $149.37 \pm 79.27$ & $7.23 \pm 2.15$ & QGY7703 & + \\
\hline Lung adenocarcinoma & 20 & $199.45 \pm 69.11$ & $8.13 \pm 2.17$ & SMMC-7721 & + \\
\hline Lung squamous cell carcinoma & 20 & $185.37 \pm 71.64$ & $7.53 \pm 2.23$ & HepG2 & + \\
\hline Lung small cell carcinoma & 19 & $146.25 \pm 83.00$ & $7.78 \pm 2.17$ & MDA-MB-231 & + \\
\hline Papillary thyroid carcinoma & 20 & $191.67 \pm 82.71$ & $7.93 \pm 2.76$ & MDA-MB-435 & + \\
\hline Hepatocarcinoma & 22 & $168.25 \pm 79.33$ & $8.47 \pm 3.18$ & MCF7 & + \\
\hline Prostate carcinoma & 25 & $145.37 \pm 75.35$ & $8.52 \pm 3.43$ & HeLa & + \\
\hline Breast cancer & 24 & $165.73 \pm 63.28$ & $7.93 \pm 2.56$ & SKOV3 & + \\
\hline Endometrial cancer & 30 & $153.32 \pm 57.00$ & $8.73 \pm 3.63$ & Нер2 & + \\
\hline Glioma & 20 & $131.50 \pm 42.59$ & $10.28 \pm 5.00$ & T24 & + \\
\hline Renal cell carcinoma & 24 & $89.61 \pm 53.73$ & $11.27 \pm 4.91$ & & \\
\hline
\end{tabular}

${ }^{\mathrm{a}}$ Mean $\pm \mathrm{SD}$ 
$50 \%$ difference from reported anti-p21Ras scFv antibodies. The KGH-R1 scFv antibody could recognize wildtype and mutated H-p21Ras, K-p21Ras, and N-p21Ras and exhibited strong immunoreactivity with human tumour cell lines and primary tumours. It is suggested that the scFv may be useful for ras signalling blockage and as a therapeutic antibody for ras-derived tumours.

\section{Additional files}

Additional file 1: The ARRIVE Guidelines Checklist. (DOC 694 kb)

\begin{abstract}
Abbreviations
scFv: Single chain fragment variable; kD: KiloDalton; GTP: Guanosine triphosphate; CDS: Coding sequences; NCBI: National Center for Biotechnology Information; IPTG: Isopropyl $\beta$-D-1-thiogalactopyranoside; SDS-PAGE: Sodium dodecyl sulfate-polyacrylamide gel electrophoresis; mAb: Monoclonal antibody; HAT: Hypoxanthine, aminopterin, thymidine; ELISA: Enzyme-linked immunosorbent assay; $V_{H}$ : Heavy chain variable region; $V_{L}$ : Light chain variable region; PBS: Phosphate buffered saline; PBST: PBS containing $0.05 \%$ tween-20; BSA: Albumin from bovine serum; HRP: Horseradish peroxidase; CDR: Complementarity-determining region; FR: Framework region; Her2: Human epidermal growth factor receptor 2.
\end{abstract}

\section{Competing interests}

The authors declare that they have no competing interests.

\section{Authors' contributions}

$J L Y$ contributed to the conception and design of the study. DXL, SJZ, YGZ, $D J Z$, LYY and HBC were involved in the acquisition of the data. All authors participated in the analysis and interpretation of the data. QF drafted the manuscript. JLY contributed to the revision of the manuscript. JLY contributed to the supervision of the study. All authors read and approved the final manuscript.

\section{Acknowledgements}

This work was supported by the grants from the National Natural Science Foundation of China (No 30872994 and No 81460464) and the Scientific and Technological key project of Yunnan Province (No 2006SG11).

\section{Author details}

${ }^{1}$ Department of Pathology, Kunming General Hospital/Kunming Medical University, Kunming 650032, Yunnan Province, China. ${ }^{2}$ Department of Molecular Biology, Kunming General Hospital/Kunming Medical University, Kunming 650032, Yunnan Province, China.

Received: 11 June 2015 Accepted: 14 February 2016

Published online: 20 February 2016

\section{References}

1. Lener M, Horn IR, Cardinale A, Messina S, Nielsen UB, Rybak SM, Hoogenboom HR, Cattaneo A, Biocca S. Diverting a protein from its cellular location by intracellular antibodies.

The case of p21Ras. Eur J Biochem. 2000:267(4):1196-205.

2. Adjei AA. Blocking oncogenic Ras signaling for cancer therapy. J Natl Cancer Inst. 2001;93(14):1062-74.

3. Xin C, Ye S, Ming Y, Shenghua Z, Qingfang M, Hongxing G, Xu S, Yuanfu X, Yuan Z, Dongmei F, et al. Efficient inhibition of B-cell lymphoma xenografts with a novel recombinant fusion protein: anti-CD20Fab-LDM. Gene Ther. 2010;17(10):1234-43

4. Sheng W, Shang Y, Miao Q, Li Y, Zhen Y. Antitumor efficacy of the scFvbased fusion protein and its enediyne-energized analogue directed against epidermal growth factor receptor. Anticancer Drugs. 2012;23(4):406-16.

5. Miao QF, Liu XY, Shang BY, Ouyang ZG, Zhen YS. An enediyne-energized single-domain antibody-containing fusion protein shows potent antitumor activity. Anticancer Drugs. 2007;18(2):127-37.
6. Bird RE, Hardman KD, Jacobson JW, Johnson S, Kaufman BM, Lee SM, Lee T, Pope $\mathrm{SH}$, Riordan GS, Whitlow M. Single-chain antigen-binding proteins. Science. 1988;242(4877):423-6.

7. Yokota T, Milenic DE, Whitlow M, Schlom J. Rapid tumor penetration of a single-chain Fv and comparison with other immunoglobulin forms. Cancer Res. 1992:52(12):3402-8.

8. Demarest SJ, Glaser SM. Antibody therapeutics, antibody engineering, and the merits of protein stability. Curr Opin Drug Discov Devel. 2008;11(5):675-87.

9. Schirrmann T, Al-Halabi L, Dubel S, Hust M. Production systems for recombinant antibodies. Front Biosci. 2008;13:4576-94.

10. Novinger $L$, Ashikaga T, Krag DN. Identification of tumor-binding scFv derived from clonally related $B$ cells in tumor and lymph node of a patient with breast cancer. Cancer Immunol Immunother. 2015;64(1):29-39.

11. Buhler $P$, Wetterauer $D$, Gierschner D, Wetterauer U, Beile UE, Wolf P. Influence of structural variations on biological activity of anti-PSMA scFv and immunotoxins targeting prostate cancer. Anticancer Res. 2010;30(9):3373-9.

12. Yao YD, Sun TM, Huang SY, Dou S, Lin L, Chen JN, Ruan JB, Mao CQ, Yu FY, Zeng MS, et al. Targeted delivery of PLK1-siRNA by ScFv suppresses Her2+ breast cancer growth and metastasis. Sci Transl Med. 2012;4(130):130-48.

13. Gallick GE, Kurzrock R, Kloetzer WS, Arlinghaus RB, Gutterman JU. Expression of p21ras in fresh primary and metastatic human colorectal tumors. Proc Natl Acad Sci U S A. 1985;82(6):1795-9.

14. Gerosa MA, Talarico D, Fognani C, Raimondi E, Colombatti M, Tridente G, De Carli L, Della Valle G. Overexpression of N-ras oncogene and epidermal growth factor receptor gene in human glioblastomas. J Natl Cancer Inst. 1989;81(1):63-7.

15. Hamdy S, Aprikian A, Begin L, Fair W, Bazinet M. Ras p21 overexpression is a late event in prostate-cancer. Int J Oncol. 1994;4(3):627-31.

16. Novara $R$, Coda $R$, Martone $T$, Vineis $P$. Exposure to aromatic amines and ras and c-erbB-2 overexpression in bladder cancer. J Occup Environ Med. 1996:38(4):390-3.

17. Murugan AK, Munirajan AK, Tsuchida N. Ras oncogenes in oral cancer: the past 20 years. Oral Oncol. 2012;48(5):383-92.

18. Saki M, Toulany M, Rodemann HP. Acquired resistance to cetuximab is associated with the overexpression of Ras family members and the loss of radiosensitization in head and neck cancer cells. Radiother Oncol. 2013;108(3):473-8

19. Schmukler E, Kloog Y, Pinkas-Kramarski R. Ras and autophagy in cancer development and therapy. Oncotarget. 2014;5(3):577-86.

20. Pylayeva-Gupta Y, Grabocka E, Bar-Sagi D. RAS oncogenes: weaving a tumorigenic web. Nat Rev Cancer. 2011;11(11):761-74.

21. Yoshida K, Hamatani K, Koide H, Ikeda H, Nakamura N, Akiyama M, Tsuchiyama H, Nakayama E, Shiku H. Preparation of anti-ras Mr 21,000 protein monoclonal antibodies and immunohistochemical analyses on expression of ras genes in human stomach and thyroid cancers. Cancer Res. 1988;48(19):5503-9.

22. Furth ME, Davis LJ, Fleurdelys B, Scolnick EM. Monoclonal antibodies to the p21 products of the transforming gene of Harvey murine sarcoma virus and of the cellular ras gene family. J Virol. 1982;43(1):294-304.

23. Hand PH, Thor A, Wunderlich D, Muraro R, Caruso A, Schlom J. Monoclonal antibodies of predefined specificity detect activated ras gene expression in human mammary and colon carcinomas. Proc Natl Acad Sci U S A. 1984:81(16):5227-31.

24. Zhou Y, Zhang J, Jin H, Chen Z, Wu Q, Li W, Yue M, Luo C, Wang M. Prokaryotic expression and refolding of EGFR extracellular domain and generation of phage display human scFv against EGFR. Biomed Pharmacother. 2013:67(8):737-43.

25. Huang CL, Yokomise H, Kobayashi S, Fukushima M, Hitomi S, Wada H. Intratumoral expression of thymidylate synthase and dihydropyrimidine dehydrogenase in non-small cell lung cancer patients treated with 5-FUbased chemotherapy. Int J Oncol. 2000;17(1):47-54.

26. Liu Y, Chang J, Chen Y, Wan B, Wang Y, Zhang G. Construction of a human scFv antibody library with $\mathrm{VH}$ regions randomized and its application. Biotechnol Lett. 2012;34(7):1203-8.

27. Chang C, Takayanagi A, Yoshida T, Shimizu N. Screening of sCFvdisplaying phages recognizing distinct extracellular domains of EGF receptor by target-guided proximity labeling method. J Immunol Methods. 2011;372(1-2):127-36.

28. Wang R, Huang A, Liu L, Xiang S, Li X, Ling S, Wang L, Lu T, Wang S. Construction of a single chain variable fragment antibody (scFv) against tetrodotoxin (TTX) and its interaction with TTX. Toxicon. 2014;83:22-34. 
29. Babaei A, Zarkesh-Esfahani SH, Gharagozloo M. Production of a recombinant anti-human CD4 single-chain variable-fragment antibody using phage display technology and its expression in Escherichia coli. J Microbiol Biotechnol. 2011;21(5):529-35.

30. Schwede T, Kopp J, Guex N, Peitsch MC. SWISS-MODEL: An automated protein homology-modeling server. Nucleic Acids Res. 2003;31(13):3381-5.

31. Wong C, Waibel R, Sheets M, Mach JP, Finnern R. Human scFv antibody fragments specific for the epithelial tumour marker MUC-1, selected by phage display on living cells. Cancer Immunol Immunother. 2001;50(2):93-101.

32. Bos JL. The ras gene family and human carcinogenesis. Mutat Res. 1988;195(3):255-71.

33. Cochet $O$, Kenigsberg M, Delumeau I, Virone-Oddos A, Multon MC, Fridman WH, Schweighoffer F, Teillaud $J$, Tocque B. Intracellular expression of an antibody fragment-neutralizing p21 ras promotes tumor regression. Cancer Res. 1998;58(6):1170-6.

34. Bayoudh L, Afrit M, Daldoul O, Zarrad M, Boussen H. [Trastuzumab (herceptin) for the medical treatment of breast cancer]. Tunis Med. 2012;90(1):6-12.

35. Servitja S, Ramos M, Gil M, Sanchez-Rovira P, Vazquez-Estevez S, Virizuela JA, Garcia-Estevez L, Velasco A, Tusquets I. Multicenter, phase II, nonrandomized study of docetaxel plus trastuzumab every 21 days as the primary therapy in metastatic breast cancer overexpressing HER2. Anticancer Drugs. 2012;23(2):239-46

36. Oflazoglu E, Audoly LP. Evolution of anti-CD20 monoclonal antibody therapeutics in oncology. MAbs. 2010;2(1):14-9.

37. Liu A, Ye Y, Chen W, Wang X, Chen F. Expression of VH-linker-V L orientation-dependent single-chain Fv antibody fragment derived from hybridoma 2E6 against aflatoxin B1 in Escherichia coli. J Ind Microbiol Biotechnol. 2015;42(2):255-62.

38. Chen W, Hu L, Liu A, Li J, Chen F, Wang X. Expression and characterization of single-chain variable fragment antibody against staphylococcal enterotoxin A in Escherichia coli. Can J Microbiol. 2014;60(11):737-43.

39. Zhu Q, Guo D, Feng L, Sun D. Expression and Purification of the scFv from hybridoma cells secreting a monoclonal antibody against S PROTEIN of PEDV. Monoclon Antib Immunodiagn Immunother. 2013;32(1):41-6.

40. Clackson T, Hoogenboom HR, Griffiths AD, Winter G. Making antibody fragments using phage display libraries. Nature. 1991;352(6336):624-8.

41. Chan CE, Chan AH, Lim AP, Hanson BJ. Comparison of the efficiency of antibody selection from semi-synthetic scFv and non-immune Fab phage display libraries against protein targets for rapid development of diagnostic immunoassays. J Immunol Methods. 2011;373(1-2):79-88.

42. Cochet $O$, Kenigsberg M, Delumeau I, Duchesne M, Schweighoffer F, Tocque B, Teillaud JL. Intracellular expression and functional properties of an anti-p21Ras scFv derived from a rat hybridoma containing specific lambda and irrelevant kappa light chains. Mol Immunol. 1998;35(17):1097-110.

43. Werge TM, Biocca S, Cattaneo A. Intracellular immunization. Cloning and intracellular expression of a monoclonal antibody to the p21 ras protein. FEBS Lett. 1990;274(1-2):193-8.

\section{Submit your next manuscript to BioMed Central and we will help you at every step:}

- We accept pre-submission inquiries

- Our selector tool helps you to find the most relevant journal

- We provide round the clock customer support

- Convenient online submission

- Thorough peer review

- Inclusion in PubMed and all major indexing services

- Maximum visibility for your research

Submit your manuscript at www.biomedcentral.com/submit 